\title{
Post-Irradiation Vickers Microhardness Development of Novel Resin Composites
}

\author{
Hanadi Yousif Marghalani* \\ Conservative Dental Science Department, \\ Faculty of Dentistry, King Abdulaziz University, Jeddah, \\ KSA 85 Prince Fawaz dist. P.O. Box 35030, Jeddah 21488, Saudi Arabia
}

Received: October 14, 2009; Revised: November 29, 2009

\begin{abstract}
The aim of this study was to evaluate the effect of post-irradiation dry aging at different periods of time on Vickers microhardness of some dental composites based on various resin matrices. Sixty four disc-shaped specimens of the resin composites were prepared in a split Teflon mold $(8 \times 2 \mathrm{~mm})$ and irradiated by Optilux 501 light cure $\left(500 \mathrm{~mW} \cdot \mathrm{cm}^{-2}\right.$ for 40 seconds) on their top side. The specimens were aged-dry in dark at 23 and $37^{\circ} \mathrm{C}$ for the following storage periods; immediate, $1 / 2$ an hour, 1, 6, 12, 24, 48 and 168 hours. The microhardness values were recorded using a Vickers Hardness Tester at $300 \mathrm{~g}$ load for 15 seconds. Results showed that Filtek ${ }^{\circledR} \mathrm{P} 90$ and Definite expressed the highest hardness value followed by Tetric Evoceram and then Premise Enamel. At each aging period, all materials demonstrated significant differences between hardness values of top and base surfaces as well as both temperatures examined $(\mathrm{P}<0.05)$. In conclusion, surface hardness developed gradually in most of the materials reaching optimum after 168 hours post-irradiation aging. Dental composites based on silorane and ormocer resin matrices achieved higher Vickers microhardness than those based on dimethacrylates resin.
\end{abstract}

Keywords: post-irradiation aging, vickers microhardness, nanohybrid composites, silorane, ormocer

\section{Introduction}

Resin composite restorative is rapidly becoming the dental material of choice for conservative and direct applications in esthetic dentistry than the conventional materials. Nowadays, the development of the esthetic dentistry resulted in increasing interest of using resin composites in high stress dental bearing areas. The most important factor that limits their use in these areas is that they are not hard enough to withstand mastication strength. The improvements in the currently available composite materials include the increase of filler content, variations in size, type and morphology of the particles, in addition to changes in the organic matrix ${ }^{1}$. These changes have conferred better mechanical properties to these materials, thus, allowing them to be used in areas subjected to great masticatory efforts ${ }^{2}$.

The advent of nanotechnology in field of dentistry is based on production of nanocomposites by improving the filler technology of submicron particle size, modification of organic matrix and silane coupling agent ${ }^{3}$. The nanotechnology is aimed to improve the physical and mechanical properties of the composite restoratives. Several studies have been focused on the filler content, particle size, and the development of new particles ${ }^{3,4}$. Many efforts have been undertaken to maximize the clinical performance nanofilled composites ${ }^{5}$. Ceramic based composites enable to yield good polishability, low wear and high gloss, while composites containing ytterbium trifluoride offer better radiopacity ${ }^{5}$. Moreover, inclusion of smaller filler particles as nano-size in the final formulation of the composites results in reduction of composite's shrinkage and improving their total mechanical properties $^{4}$.

Recently, the main focus in the further development of modern restorative composites is targeted on the modification of polymer matrix or fillers aiming at reduction of polymerization shrinkage and stress, increasing the degree of monomers conversion and improving their overall properties. Furthermore, nanotechnology involves several researches on different resin matrices that are mainly based on the development of new monomers. Some of novel resin polymers such as silorane, thiol-ene oligomer, hyperbranched (dendritic) monomers, polyhedral oligomeric silsesquioxanes methacrylate (POSS-MA) and pure ormocer have been developed ${ }^{6-8}$.

Initial efforts were based on developing monomers or comonomers as epoxies that potentially expand upon polymerization ${ }^{9}$. However, the newly developed silorane-based composite demonstrated a ring-opening expansion polymerization mechanism which reduces the internal shrinkage stress $^{6}$. In addition to low polymerization shrinkage that characterizes this composite, it revealed low mutagenic potential, water sorption, solubility and cusp deflection ${ }^{10,11}$. Apart from the composite based on expanding ring-opening resin during the polymerization process, ormocer, however, is based on inorganic-organic hybrid polymers that are nearly as hard as glass aiming to reduce shrinkage. Ormocer is formed by polycondensation of silicone alkoxide precursors yielding a 3-dimensional SiliconeOxide-Silicone network of inorganic-organic copolymer which is polymerized by their methacrylate functionality ${ }^{8}$.

Adequate surface hardness of the resin composites is important to obtain optimum clinical performance of the restoratives in stress dental bearing areas. Hardness is a surface property defined as the resistance of a material to permanent indentation or penetration. The composite's surface hardness and the effect of post-irradiation aging have been studied extensively by many investigators ${ }^{12-14}$. It has been reported that the hardness of inorganic fillers has a direct effect on the material's hardness ${ }^{15}$. In general, the increase of particle size increases the strength as well as the surface hardness of composite. Moreover, after polymerization, the solidified polymer matrix that is formed plays a role in hardness development. It has been shown previously that monomers have not participated in polymerization reactions lead to a decrease in hardness ${ }^{16}$. Therefore, the purpose of this study was to determine the effect of post-irradiation dry aging on Vickers microhardness of some novel composites based on differ- 
ent resin matrices over periods of time after polymerization; at two common temperatures.

\section{Materials and Methods}

The four resin composites investigated in the present study are tabulated in Table 1. They are two nanohybrid dimethacrylate-based composites: (Tetric evoceram and Premise enamel), one cationic composite (Filtek P90), and one ormocer (Definite).

\subsection{Specimen preparation and group organization}

Sixty four disc-shaped specimens $(8 \mathrm{~mm}$ diameter $\times 2 \mathrm{~mm}$ thick) of the resin composites were fabricated in a split Teflon mold at room temperature. The resin composite material was gently packed inside the mold which was rested on a glass plate $(76 \times 26 \times 1 \mathrm{~mm}$ Surgipath glass). The upper and lower surfaces of the unpolymerized specimen were covered with thin Mylar strips (KerrHawe Neos Dent, Bioggio, Switzerland). Then another glass plate was compressed carefully on top of the specimen to remove the excess of the material giving a flat surface.

The glass slide was then removed, leaving the Mylar strip, after which the light-curing process was initiated. The resin composites were irradiated by a conventional halogen light curing unit (Optilux ${ }^{\circledR}$ 501, SDS, Kerr, Danbury, CT, USA) at $500 \mathrm{~mW} . \mathrm{cm}^{-2}$ for 40 seconds. The polymerization of the disc was carried out on the top side at $0.1 \mathrm{~mm}$ against the Mylar strip surface. The power density of the curing light unit was periodically monitored with an external handheld radiometer (Demetron/ Kerr, Danburry, CT, USA).

The hardened specimens were then removed from the mold and lightly finished manually from both sides after the preparation. This finishing procedure was carried out with 1000 grit silicone carbide (SiC) abrasive paper under running-coolant water followed by polishing with 2000 grit $\mathrm{SiC}$ paper as well as 5 and $1 \mu \mathrm{m}$ aluminum oxide slurry pastes for 5 seconds each step. This will allow removal of a weak resin-rich layer giving a smooth-flat testing surface. Afterwards, the examined surface was assessed for any major defects or scratches by stereo-microscope (Meiji ${ }^{\circledR}$ Techno America, San Jose, CA., USA). The specimens were then randomly divided into two groups; the first group was aged-dry in dark bottles at $23 \pm 0.5^{\circ} \mathrm{C}$ and the second one was aged similarly but inside incubator at $37 \pm 0.5{ }^{\circ} \mathrm{C}$. Each of the previous groups was further divided into eight sub-groups according to the following storage (aging) periods; immediate for 5 minutes, $1 / 2$ an hour, 1, 6, 12, 24, 48 and 168 hours (1 week).

\subsection{Vickers surface microhardness test}

The microhardness values of the upper and lower surfaces were measured with a Vickers micro-Hardness Tester (HMV-2 Shimadzu, Shimadzu ${ }^{\circledR}$ corp., Kyoto, Japan) using a diamond pyramid microindenter with a $136^{\circ}$ angle between the opposing faces. The test was conducted at room temperature $\left(23 \pm 1^{\circ} \mathrm{C}\right)$ under a load of $300 \mathrm{~g}$ for 15 seconds. The Vickers hardness number (VHN) was obtained with the following Equation 1:

$$
\mathrm{VHN}=1854.4 \mathrm{P} / \mathrm{d}^{2}
$$

where $P$ is the applied load in grams (or $\mathrm{N}=$ Newton) and $d$ is the average length of the diagonal of indentation measured in mm. Five equally spaced square indentations were randomly made on top as well as base side of each specimen ( $\mathrm{n}=5$ per each side). They were not placed closer than $1 \mathrm{~mm}$ to either adjacent indentations or to the margin of the specimens. They were measured after dry aging at the above mentioned time-intervals and the average was determined. The readings were recorded immediately after removal of the indenter to minimize the effects of elastic recovery of polymers on the results.
Data were analyzed by SPSS software (Version 11.5, SPSS ${ }^{\circledR}$ Inc., Chicago, Illinois, USA) utilizing two-factor analysis of variance (ANOVA) to determine significant differences between the two independent variables (materials and post-irradiation times) at 0.05 level of significance. If there is a significant interaction between them, one-factor ANOVA and post-hoc multiple comparison Tukey's test were used to detect the differences between the microhardness values within each variable. Independent t-test was used to evaluate the differences in microhardness between the top and base surfaces as well as the two temperatures in each aging group.

\section{Results}

The Vickers micohardness (VHN) mean and standard deviation values as a function of the post-irradiation aging times for top and base surfaces of the composite specimens at two different temperatures are summarized in Table 2 and displayed graphically in Figure 1 and 2. Two-factor ANOVA revealed high significant differences of the hardness values among the four composites examined and the eight post-irradiation aging periods $(\mathrm{p}=0.000)$. Furthermore, it indicated a high significant interaction between these two independent variables $(p=0.000)$. Therefore, the VHN of the material was dependent on post-irradiation aging time, thus, one-factor ANOVA was used to analyze the significant differences.

The one-factor ANOVA demonstrated high significant differences between the materials for the micohardness at each aging time examined $(\mathrm{p}<0.05)$ with some exceptions. For example, no significant differences were detected in microhardness on the top surface of Definite and Tetric Evoceram after 6 and 12 hours at $37^{\circ} \mathrm{C}$, and after 168 hours at $23{ }^{\circ} \mathrm{C}$. Furthermore, independent t-test showed high significant differences between micohardness values of top and base surfaces for all the composite materials at 23 and $37^{\circ} \mathrm{C}(\mathrm{p}<0.05)$. Moreover, the same test showed high significant differences between micohardness values at the two temperatures tested with some exceptions. At 23 and $37{ }^{\circ} \mathrm{C}$, post-irradiation hardness values of all materials recorded after 24,48 and 168 hours were higher and statistically different $(\mathrm{p}<0.05)$ from those measured 5 minutes after light curing.

Most of the materials investigated showed the lowest microhardness values (ranged between 27.1 for Premise Enamel at base surface and 53.6 for Filtek ${ }^{\circledR}$ P90 at top surface) when measured immediately after preparation. On the contrary, the highest microhardness values (ranged between 57.1 for Premise Enamel at base surface and 89.4 for Filtek ${ }^{\circledR}$ P90 at top surface) were recorded after 168 hours postirradiation aging. A gradual development of surface hardness value was observed with Filtek ${ }^{\circledR}$ P90 resin composite reaching optimum after 168 hours post-irradiation aging. The highest hardness peak value was started after 24 hours post-irradiation storage and then it was either maintained constant as in some resin composites (Definite and Premise Enamel at $23{ }^{\circ} \mathrm{C}$ ) or it was raised more after one week post-irradiation aging as in Filtek ${ }^{\circledR}$ P90 and Tetric Evoceram.

At $37{ }^{\circ} \mathrm{C}$, Filtek ${ }^{\circledR} \mathrm{P} 90$ and Definite expressed the highest hardness value followed by Tetric Evoceram and then Premise Enamel which showed the lowest surface microhardness. It was noted that at a relatively high body-temperature $\left(37^{\circ} \mathrm{C}\right)$, the Vickers microhardness values for both top and base surfaces of the specimens were higher than those measured at $23{ }^{\circ} \mathrm{C}$. All samples demonstrated significantly harder top surfaces than base ones $(\mathrm{p}<0.05)$. The hardest top surface was observed in Filtek ${ }^{\circledR}$ P90 followed by Definite when they were aged for 168 hours at $37{ }^{\circ} \mathrm{C}$ (89.4 and 81.5 , respectively). However, the base surface of Premise Enamel specimens expressed the lowest hardness value (27.1) when they were measured immediately after the preparation at $23{ }^{\circ} \mathrm{C}$. 


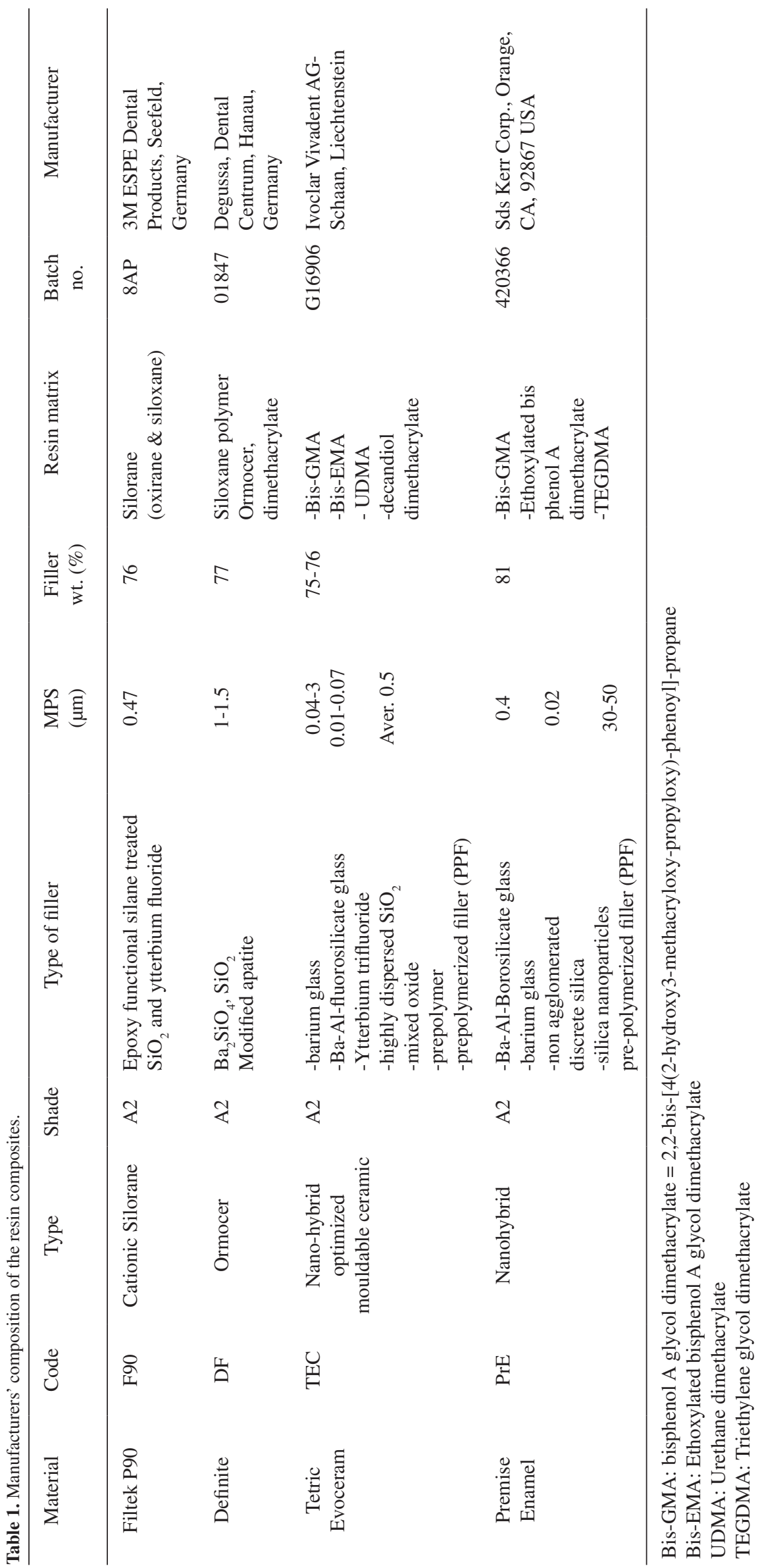




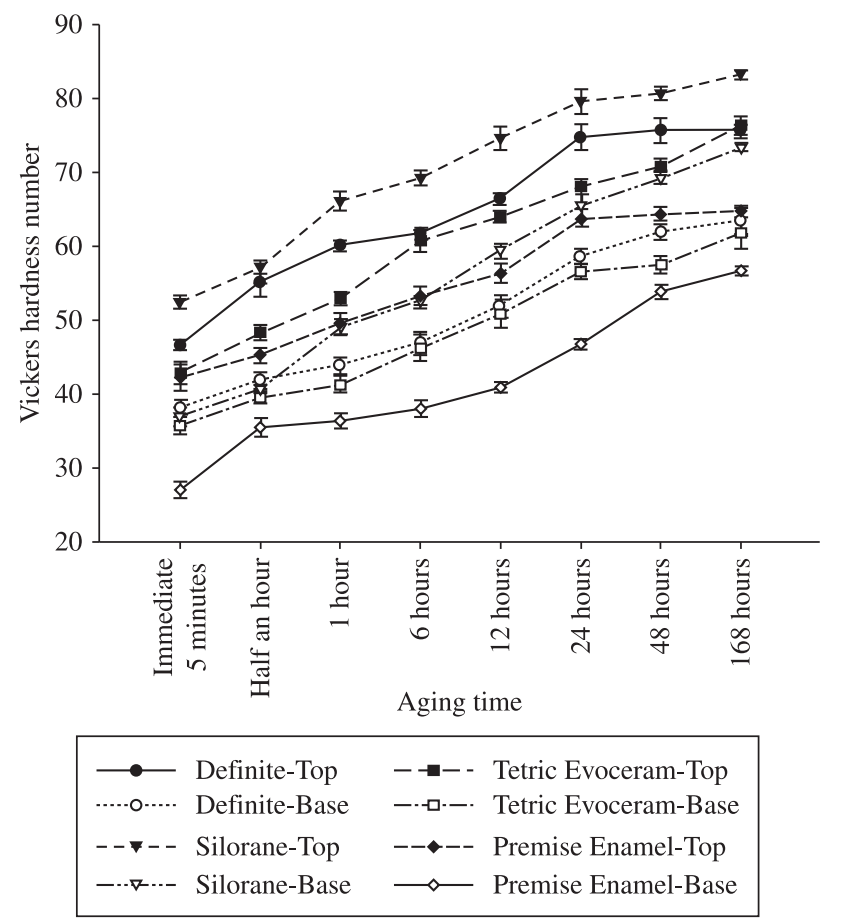

Figure 1. Vickers surface microhardness of novel resin composites aged dry at $23{ }^{\circ} \mathrm{C}$.

\section{Discussion}

Vickers microhardness test was selected for this study because it is relatively a simple technique, very popular and reliable for obtaining the results. Additionally, it is considered by several authors as an indicator for the degree of polymerization of resin materials and used commonly as indirect method to evaluate degree of cure ${ }^{13,14}$. Surface microhardness is considered as an indicative factor of the mechanical strength of a resin and correlates well to the material's rigidity ${ }^{17}$. In the current study, all test samples were submitted to the same parameters of light-curing method and initial finishing. Slight finishing and polishing were performed for the specimen's surface after polymerization in order to remove the softer resin-rich layer of material and exposing the hardest one. Removal of this weak superficial layer is essential to produce a relatively stable surface with increasing predictability of developing high surface hardness. In this study, $2 \mathrm{~mm}$ specimen's thickness of resin composites may be sufficient to allow favorable depth of cure for light penetration and performing the hardness test. Moreover, dry aging of the specimens were selected because it has been noted that a rapid polymerization and increase of hardness were observed in dry condition and elevated temperature ${ }^{14}$. This is inconsistent with a previous work ${ }^{18}$. Hardness measurements were performed at top-irradiated and base-nonirradiated surfaces of the specimens to ensure proper cure of the resin.

Composite-related factors affecting strongly surface hardness of the material include filler particle size, type, morphology, distribution, volume fraction and diluent's concentration. A positive correlation has been established between the hardness and inorganic filler content of resin composites ${ }^{1,2}$. Composites with harder filler particles and higher filler load exhibit higher surface hardness ${ }^{2}$. It was found that composites with round filler particles had the highest filler loading, resulting in the highest hardness, while those with irregular-shaped filler particles had intermediate filler loading and hardness ${ }^{19}$. Additionally, resin composition, type and degree of polymerization significantly affect the hardness of the restorative materials ${ }^{20,21}$. The
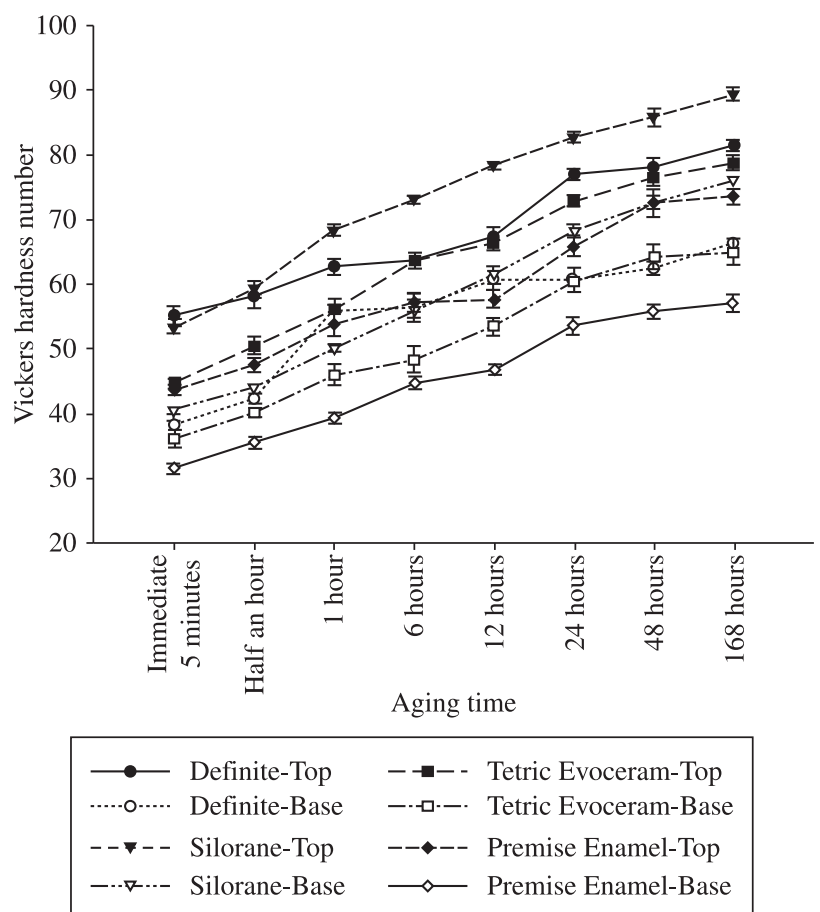

Figure 2. Vickers surface microhardness of novel resin composites aged dry at $37^{\circ} \mathrm{C}$.

polymerizing system and degree of conversion of resin composites may influence the hardness. The correlation between surface hardness and degree of conversion of resin materials has been demonstrated in previous studies ${ }^{21,22}$. However, the light-related factors that may affect hardness include light intensity, the distance between light-curing guide to the material and exposure time ${ }^{23}$.

The data of this study revealed that silorane-based (Filtek ${ }^{\circledR}$ P90) and ormocer-based (Definite) composites demonstrated higher VHN than Premise Enamel. Although the later composite is nanohybrid and expressed high filler content in its composition. Premise Enamel showed the lowest surface hardness among the materials examined, which can be attributed to the presence of small filler particles that causes a light scattering, thus, decreasing the effectiveness of the curing light ${ }^{3,5}$. This is in the contrary with a previous study found that high filler content increases the surface hardness ${ }^{19}$.

The higher surface hardness of Filtek ${ }^{\circledR}$ P90 and Definite after the post-irradiation aging may be related to their composition. Filtek $\mathrm{P} 90$ promoted the highest VHN values which can be attributed to the cationic polymerization reaction. It is characterized by continuous ring-opening expansion initiated at the time of curing and promoted further crosslinking and hardening of the entire matrix ${ }^{24,25}$. This cationic reaction is initiated by an acidic cation that allows stress relaxation, thereby, reducing polymerization contraction of the composite $^{6,25}$. The Filtek ${ }^{\circledR} \mathrm{P} 90$ composite is characterized by a special resin matrix chemistry that differs from the commonly known dental composites based on dimethacrylate resin. It is made up of silorane resin, which composed mainly of siloxane and oxirane moieties ${ }^{6}$. This new monomer is capable of being polymerized and continuing the cationic reaction in dark which is called self or dark polymerization ${ }^{26}$. The dark reaction usually is time dependent and may attribute to the strength and hardness of the material ${ }^{27}$.

The microhardness recorded immediately after polymerization showed lesser value than that measured after $1 / 2$ an hour postirradiation aging period. After the cessation of light irradiation, the 
Table 2. Surface microhardness of the novel resin composites after dry aging.

\begin{tabular}{|c|c|c|c|c|c|c|c|c|}
\hline \multirow{3}{*}{$\begin{array}{l}\text { Dry storage } \\
\text { time }\end{array}$} & \multicolumn{8}{|c|}{$23{ }^{\circ} \mathrm{C}$} \\
\hline & \multicolumn{2}{|c|}{ Definite } & \multicolumn{2}{|c|}{ Filtek $^{\circledR}$ P90 } & \multicolumn{2}{|c|}{ Tetric Evoceram } & \multicolumn{2}{|c|}{ Premise Enamel } \\
\hline & Top & Base & Top & Base & Top & Base & Top & Base \\
\hline 5 minutes & $\begin{array}{c}46.62 \\
(0.712)^{\mathrm{a}}\end{array}$ & $\begin{array}{c}38.16 \\
(1.246)^{\mathrm{a}}\end{array}$ & $\begin{array}{c}52.50 \\
(0.812)^{\mathrm{a}}\end{array}$ & $\begin{array}{c}37.02 \\
(1.238)^{\mathrm{a}}\end{array}$ & $\begin{array}{c}42.72 \\
(1.299)^{\mathrm{a}}\end{array}$ & $\begin{array}{c}35.82 \\
(1.221)^{\mathrm{a}}\end{array}$ & $\begin{array}{c}42.56 \\
(1.889)^{\mathrm{a}}\end{array}$ & $\begin{array}{c}27.10 \\
(1.170)^{\mathrm{a}}\end{array}$ \\
\hline Half an hour & $\begin{array}{c}55.18 \\
(2.054)^{\mathrm{b}}\end{array}$ & $\begin{array}{c}41.90 \\
(1.111)^{\mathrm{b}}\end{array}$ & $\begin{array}{c}57.26 \\
(0.868)^{\mathrm{b}}\end{array}$ & $\begin{array}{c}40.82 \\
(0.421)^{b}\end{array}$ & $\begin{array}{c}48.40 \\
(1.042)^{\mathrm{b}}\end{array}$ & $\begin{array}{c}39.58 \\
(0.756)^{\mathrm{b}}\end{array}$ & $\begin{array}{c}45.28 \\
(0.993)^{\mathrm{b}}\end{array}$ & $\begin{array}{c}35.56 \\
(1.313)^{\mathrm{b}}\end{array}$ \\
\hline 1 hour & $\begin{array}{c}60.02 \\
(0.669)^{c}\end{array}$ & $\begin{array}{c}43.90 \\
(1.190)^{\mathrm{b}}\end{array}$ & $\begin{array}{c}66.06 \\
(1.270)^{\mathrm{c}}\end{array}$ & $\begin{array}{c}49.14 \\
(1.016)^{\mathrm{c}}\end{array}$ & $\begin{array}{c}52.94 \\
(0.862)^{\mathrm{c}}\end{array}$ & $\begin{array}{c}41.36 \\
(1.135)^{\mathrm{b}}\end{array}$ & $\begin{array}{c}49.50 \\
(1.437)^{\mathrm{c}}\end{array}$ & $\begin{array}{c}36.44 \\
(1.029)^{c}\end{array}$ \\
\hline 6 hours & $\begin{array}{c}61.70 \\
(0.822)^{\mathrm{c}}\end{array}$ & $\begin{array}{c}46.96 \\
(1.568)^{c}\end{array}$ & $\begin{array}{c}69.16 \\
(0.948)^{\mathrm{d}}\end{array}$ & $\begin{array}{c}52.74 \\
(0.619)^{\mathrm{d}}\end{array}$ & $\begin{array}{c}60.90 \\
(1.552)^{\mathrm{d}}\end{array}$ & $\begin{array}{c}46.34 \\
(1.858)^{\mathrm{c}}\end{array}$ & $\begin{array}{c}53.10 \\
(1.517)^{\mathrm{d}}\end{array}$ & $\begin{array}{c}38.06 \\
(1.126)^{\mathrm{d}}\end{array}$ \\
\hline 12 hours & $\begin{array}{c}66.40 \\
(0.803)^{\mathrm{d}}\end{array}$ & $\begin{array}{c}51.80 \\
(1.471)^{\mathrm{d}}\end{array}$ & $\begin{array}{c}74.58 \\
(1.616)^{\mathrm{e}}\end{array}$ & $\begin{array}{c}59.40 \\
(0.877)^{\mathrm{e}}\end{array}$ & $\begin{array}{c}63.90 \\
(0.721)^{\mathrm{e}}\end{array}$ & $\begin{array}{c}50.90 \\
(1.927)^{\mathrm{d}}\end{array}$ & $\begin{array}{c}56.32 \\
(1.486)^{\mathrm{e}}\end{array}$ & $\begin{array}{c}40.96 \\
(0.744)^{\mathrm{e}}\end{array}$ \\
\hline 24 hours & $\begin{array}{c}74.74 \\
(1.711)^{\mathrm{e}}\end{array}$ & $\begin{array}{c}58.66 \\
(0.994)^{\mathrm{e}}\end{array}$ & $\begin{array}{c}79.54 \\
(1.635)^{\mathrm{f}}\end{array}$ & $\begin{array}{c}65.48 \\
(1.516)^{\mathrm{f}}\end{array}$ & $\begin{array}{c}68.04 \\
(1.011)^{\mathrm{f}}\end{array}$ & $\begin{array}{c}56.58 \\
(1.050)^{\mathrm{e}}\end{array}$ & $\begin{array}{c}63.74 \\
(1.195)^{\mathrm{f}}\end{array}$ & $\begin{array}{c}46.72 \\
(0.760)^{\mathrm{f}}\end{array}$ \\
\hline 48 hours & $\begin{array}{c}75.58 \\
(1.585)^{\mathrm{e}}\end{array}$ & $\begin{array}{c}61.88 \\
(0.998)^{\mathrm{f}}\end{array}$ & $\begin{array}{c}80.64 \\
(0.885)^{\mathrm{f}}\end{array}$ & $\begin{array}{c}69.24 \\
(0.764)^{\mathrm{g}}\end{array}$ & $\begin{array}{c}70.68 \\
(1.224)^{g}\end{array}$ & $\begin{array}{c}57.50 \\
(1.241)^{\mathrm{e}}\end{array}$ & $\begin{array}{c}64.36 \\
(0.913)^{\mathrm{f}}\end{array}$ & $\begin{array}{c}53.80 \\
(0.967)^{g}\end{array}$ \\
\hline 168 hours & $\begin{array}{c}75.42 \\
(0.807)^{\mathrm{e}} \\
\end{array}$ & $\begin{array}{c}63.40 \\
(1.776)^{\mathrm{f}} \\
\end{array}$ & $\begin{array}{c}83.18 \\
(0.716)^{\mathrm{g}} \\
\end{array}$ & $\begin{array}{c}73.36 \\
(0.586)^{\mathrm{h}} \\
\end{array}$ & $\begin{array}{c}76.24 \\
(1.238)^{\mathrm{h}}\end{array}$ & $\begin{array}{c}61.78 \\
(2.068)^{\mathrm{f}} \\
\end{array}$ & $\begin{array}{c}64.68 \\
(0.779)^{\mathrm{f}} \\
\end{array}$ & $\begin{array}{c}56.64 \\
(0.691)^{\mathrm{h}}\end{array}$ \\
\hline \multirow{3}{*}{$\begin{array}{l}\text { Dry storage } \\
\text { time }\end{array}$} & \multicolumn{8}{|c|}{$37^{\circ} \mathrm{C}$} \\
\hline & \multicolumn{2}{|c|}{ Definite } & \multicolumn{2}{|c|}{ Filtek $^{\circledR}$ P90 } & \multicolumn{2}{|c|}{ Tetric Evoceram } & \multicolumn{2}{|c|}{ Premise Enamel } \\
\hline & Top & Base & Top & Base & Top & Base & Top & Base \\
\hline 5 minutes & $\begin{array}{c}55.14 \\
(1.710)^{\mathrm{a}}\end{array}$ & $\begin{array}{c}38.14 \\
(0.658)^{\mathrm{a}}\end{array}$ & $\begin{array}{c}53.46 \\
(1.122)^{\mathrm{a}}\end{array}$ & $\begin{array}{c}40.52 \\
(0.581)^{\mathrm{a}}\end{array}$ & $\begin{array}{c}44.28 \\
(1.101)^{\mathrm{a}}\end{array}$ & $\begin{array}{c}36.18 \\
(1.457)^{\mathrm{a}}\end{array}$ & $\begin{array}{c}43.70 \\
(0.714)^{\mathrm{a}}\end{array}$ & $\begin{array}{c}31.58 \\
(0.814)^{\mathrm{a}}\end{array}$ \\
\hline Half an hour & $\begin{array}{c}58.08 \\
(1.763)^{\mathrm{b}}\end{array}$ & $\begin{array}{c}42.26 \\
(0.924)^{\mathrm{b}}\end{array}$ & $\begin{array}{c}59.26 \\
(1.361)^{\mathrm{b}}\end{array}$ & $\begin{array}{c}43.82 \\
(0.858)^{\mathrm{b}}\end{array}$ & $\begin{array}{c}50.46 \\
(1.330)^{\mathrm{b}}\end{array}$ & $\begin{array}{c}40.10 \\
(0.640)^{\mathrm{b}}\end{array}$ & $\begin{array}{c}47.50 \\
(1.147)^{\mathrm{b}}\end{array}$ & $\begin{array}{c}35.54 \\
(0.796)^{b}\end{array}$ \\
\hline 1 hour & $\begin{array}{c}62.72 \\
(1.163)^{\mathrm{c}}\end{array}$ & $\begin{array}{c}55.28 \\
(1.532)^{\mathrm{c}}\end{array}$ & $\begin{array}{c}68.26 \\
(0.904)^{\mathrm{c}}\end{array}$ & $\begin{array}{c}50.10 \\
(0.671)^{\mathrm{c}}\end{array}$ & $\begin{array}{c}55.90 \\
(1.803)^{\mathrm{c}}\end{array}$ & $\begin{array}{c}46.04 \\
(1.668)^{\mathrm{c}}\end{array}$ & $\begin{array}{c}53.96 \\
(1.942)^{\mathrm{c}}\end{array}$ & $\begin{array}{c}39.30 \\
(0.812)^{\mathrm{c}}\end{array}$ \\
\hline 6 hours & $\begin{array}{c}63.66 \\
(1.286)^{\mathrm{c}}\end{array}$ & $\begin{array}{c}56.30 \\
(1.444)^{\mathrm{c}}\end{array}$ & $\begin{array}{c}72.98 \\
(0.729)^{\mathrm{d}}\end{array}$ & $\begin{array}{c}56.00 \\
(1.687)^{\mathrm{d}}\end{array}$ & $\begin{array}{c}63.80 \\
(1.079)^{\mathrm{d}}\end{array}$ & $\begin{array}{c}48.36 \\
(2.104)^{\mathrm{c}}\end{array}$ & $\begin{array}{c}57.04 \\
(1.509)^{\mathrm{c}}\end{array}$ & $\begin{array}{c}44.78 \\
(1.011)^{\mathrm{c}}\end{array}$ \\
\hline 12 hours & $\begin{array}{c}67.32 \\
(1.571)^{\mathrm{d}}\end{array}$ & $\begin{array}{c}60.86 \\
(1.914)^{\mathrm{d}}\end{array}$ & $\begin{array}{c}78.38 \\
(0.709)^{\mathrm{e}}\end{array}$ & $\begin{array}{c}61.46 \\
(1.203)^{\mathrm{e}}\end{array}$ & $\begin{array}{c}66.32 \\
(1.101)^{\mathrm{d}}\end{array}$ & $\begin{array}{c}53.50 \\
(1.414)^{\mathrm{d}}\end{array}$ & $\begin{array}{c}57.72 \\
(1.352)^{\mathrm{d}}\end{array}$ & $\begin{array}{c}46.76 \\
(0.709)^{\mathrm{d}}\end{array}$ \\
\hline 24 hours & $\begin{array}{c}76.96 \\
(0.984)^{\mathrm{e}}\end{array}$ & $\begin{array}{c}60.64 \\
(1.927)^{\mathrm{d}}\end{array}$ & $\begin{array}{c}82.70 \\
(0.819)^{\mathrm{f}}\end{array}$ & $\begin{array}{c}68.36 \\
(0.817)^{\mathrm{f}}\end{array}$ & $\begin{array}{c}73.02 \\
(0.785)^{\mathrm{e}}\end{array}$ & $\begin{array}{c}60.26 \\
(0.835)^{\mathrm{e}}\end{array}$ & $\begin{array}{c}65.84 \\
(1.460)^{\mathrm{e}}\end{array}$ & $\begin{array}{c}53.64 \\
(1.358)^{\mathrm{e}}\end{array}$ \\
\hline 48 hours & $\begin{array}{c}78.08 \\
(1.489)^{\mathrm{e}}\end{array}$ & $\begin{array}{c}62.42 \\
(1.008)^{\mathrm{d}}\end{array}$ & $\begin{array}{c}85.88 \\
(1.385)^{\mathrm{g}}\end{array}$ & $\begin{array}{c}72.66 \\
(2.273)^{\mathrm{g}}\end{array}$ & $\begin{array}{c}76.58 \\
(1.326)^{\mathrm{f}}\end{array}$ & $\begin{array}{c}64.24 \\
(1.967)^{\mathrm{f}}\end{array}$ & $\begin{array}{c}72.64 \\
(0.934)^{\mathrm{f}}\end{array}$ & $\begin{array}{c}55.88 \\
(1.207)^{\mathrm{f}}\end{array}$ \\
\hline 168 hours & $\begin{array}{c}81.52 \\
(0.832)^{\mathrm{f}}\end{array}$ & $\begin{array}{c}66.18 \\
(0.909)^{\mathrm{e}}\end{array}$ & $\begin{array}{c}89.40 \\
(0.967)^{\mathrm{h}}\end{array}$ & $\begin{array}{c}76.18 \\
(1.494)^{\mathrm{h}}\end{array}$ & $\begin{array}{c}78.76 \\
(1.152)^{\mathrm{f}}\end{array}$ & $\begin{array}{c}65.42 \\
(0.192)^{\mathrm{f}}\end{array}$ & $\begin{array}{c}73.14 \\
(0.297)^{\mathrm{f}}\end{array}$ & $\begin{array}{c}57.10 \\
(1.298)^{\mathrm{f}}\end{array}$ \\
\hline
\end{tabular}

*Superscript letters indicate homogenous subsets (within which $\mathrm{p}>0.05$ ) where comparison has been made with respect to post-aged storage periods for each composite.

surface hardness did not remain steady but continued to raise after $1 / 2$ an hour reaching high level at 24 and 168 hours. All the materials investigated were significantly harder at 168 hours compared to other aging periods examined. Previous studies revealed a significant improvement in hardness following post-curing ${ }^{13,14,28}$. Approximately, $75 \%$ of the polymerization reaction of resin composites takes place during the first 10 minutes and continues for a period of 24 hours ${ }^{29,30,1}$. This may explain the slight increase in hardness after 1 day, which is in agreement with previous studies ${ }^{28,31}$.

Change in the hardness property may reflect the state of curing the material and the continuation of the setting reaction ${ }^{32}$. The polymerization reaction cannot be considered finished after exposure to light due to the presence of what is called "dark polymerization".
This gradual development of surface hardness of the materials may be correlated to a substantial increase in the degree of polymerization or maturation status of the material ${ }^{28}$. It can be explained by the presence of a temporary excess of free volume of monomers with enough mobility that allows molecules to still interact at lower rates ${ }^{31}$. It has been reported that the values of resin conversion for most of the commercial dental composites vary from $40-75 \%{ }^{33,29}$. This incomplete conversion resulted from the type of the material and polymerization may yield in 25 to $60 \%$ of nonreacted residual monomers. These free monomers can continue the polymerization reaction by increasing temperature ${ }^{34}$. In this study, it was noted that when the composites aged at body temperature $\left(37^{\circ} \mathrm{C}\right)$, the hardness increases. Therefore, temperature has an influence on the degree of conversion and final 
polymerization of the composites. This can be explained by the fact that increasing temperature will cause acceleration of the mobility and polymerization rate of remaining free monomers. Previously, it has been shown that surface hardness of dental composites is significantly affected by temperature ${ }^{35,36}$.

Moreover, high VHN value exhibited by Definite can be explained by its composition which is based on ormocer (organically modified ceramics) composed of inorganic-organic hybrid copolymers that are nearly as hard as glass. It was previously found that larger filler particles of hybrid composite could be a possible consequence of increasing hardness ${ }^{8}$. A previous result has shown that the ceramic filler produced higher hardness of a composite ${ }^{15}$. Ormocer-based composite has a Siloxane polymer made up of a multifunctional polycondensate matrix backbone with polymerizable organic units formed by polycondensation ${ }^{8}$. This reaction yielded 3-D polymeric inorganic condensates forming a complex network made at a nanoscale. The network allows the incorporation of fillers in order to adjust the ormocer's properties ${ }^{8}$. Therefore, this high-density network of organic matrix together with the presence of hard-glass fillers yielding a hard structure may result into superior surface hardness of the ormocer composite $^{8}$. This is almost in agreement with Cefaly's study found that Definite-ormocer was significantly hard, but in contradiction with the finding of Manhart ${ }^{37,38}$.

On the other hand, the nanohybrid Tetric Evoceram composite presented the less hard material compared to Filtek ${ }^{\circledR}$ P90 and Definite. The relatively low filler content and the smaller filler size of this composite may contribute to their low VHN. Tetric Evoceram composite is composed of UDMA resin that may cause a high degree of monomers conversion. The latter can be due to low viscosity of UDMA resin, which increases the mobility of monomers ${ }^{20}$. It was found that adding TEGDMA to the resin will improve mechanical properties by increasing the molecular mobility and degree of conversion up to $70 \%{ }^{39}$. However, it has been shown that low microhardness associated with higher TEGDMA concentration may be related to its hydrophilicity ${ }^{39}$. In the contrary, it has been shown previously that nanofilled resin composite gave the highest VHN compared to mirofilled and microhybrid composites. This may be attributed to the presence of small agglomerated or non-agglomerated nanofillers that occupy the spaces between the slightly larger particles resulting in increased filler load in the composite ${ }^{40}$.

The composite materials showed higher hardness values on the top surface than the base one in all test groups. This can be explained by the higher degree of polymerization that occurs as a result of the closest contact of the light-curing guide to the top surface. When the curing light is applied to composite resin, some of the light rays are absorbed while others are scattered by the composite resulting in reduction or attenuation of light intensity which deceases the effectiveness of cure at the base surface ${ }^{23,32}$. At the relatively high temperature $\left(37^{\circ} \mathrm{C}\right)$, the base surface of the specimens showed an increase in the microhardness values, which may be attributed to the dark polymerization of the resin.

\section{Conclusions}

In conclusion, the microhardness of resin composites is influenced by the composition of the resin matrix, temperature and post-irradiation aging. Filtek ${ }^{\circledR}$ P90 based on silorane and Definite based on ormocer resins expressed the highest VHN as compared to nanohybrid composites. Post-irradiation dry aging of silorane-based composite allows gradual development of hardness, which may be attributed to continuous ring-opening reaction known as self or dark polymerization. Definite-ormocer based composite exhibited high
VHN due to the presence of unique organically modified ceramics of polycondesate organic-inorganic oligomers.

\section{References}

1. Chung KH and Greener EH. Correlation between degree of conversion, filler concentration and mechanical properties of posterior composite resins. Journal of Oral Rehabilitation. 1990; 17(5):487-94.

2. Kim KH, Ong JL and Okuno O. The effect of filler loading and morphology on the mechanical properties of contemporary composites. Journal of Prosthetic Dentistry. 2002; 87(6):642-9.

3. Beun S, Glorieux T, Devaux J, Vreven J and Leloup G. Characterization of nanofilled compared to universal and microfilled composites. Dental Materials. 2007; 23(1):51-9.

4. Condon JR and Ferracane JL. Reduced polymerization stress through non-bonded nanofiller particles. Biomaterials. 2002; 23(18):3807-15.

5. Mitra SB, Wu D and Holmes BN. An application of nanotechnology in advanced dental materials. The Journal of the American Dental Association. 2003; 134(10):1382-90.

6. Guggenberger R and Weinmann W. Exploring beyond methacrylates. American Journal of Dentistry. 2000; 13(Spec No):82D-4D.

7. Fong H, Dickens SH and Flaim GM. Evaluation of dental restorative composites containing polyhedral oligomeric silsesquioxane methacrylate. Dental Materials. 2005; 21(6):520-9.

8. Haas K and Wolter H. Synthesis, properties and applications of inorganic-organic copolymers (ORMOCERs). Current Opinion in Solid State and Materials Science. 1999; 4(6):571-80.

9. Bowen RL. Use of epoxy resins in restorative materials. Journal of Dental Research. 1956; 35(3):360-9.

10. Schweikl H, Schmalz G and Weinmann W. Mutagenic activity of structurally related oxiranes and siloranes in Salmonella typhimurium. Mutation Research. 2002; 521(1-2):19-27.

11. Palin WM, Fleming GJ, Nathwani H, Burke FJ and Randall RC. In vitro cuspal deflection and microleakage of maxillary premolars restored with novel low-shrink dental composites. Dental Materials. 2005; 21(4):324-35.

12. Yap AU. Post-irradiation hardness of resin-modified glass ionomer cements and a polyacid-modified composite resin. Journal of Materials Science: Materials in Medicine. 1997; 8(7):413-6.

13. Leung R, Fan P and Johnston W. Post-irradiation Polymerization of Visible Light-activated Composite Resin. Journal of Dental Research. 1983; 62(3):363-65.

14. Watts DC, Amer OM and Combe EC. Surface hardness development in light-cured composites. Dental Materials. 1987; 3(5):265-9.

15. Roy $\mathrm{S}$ and Basu B. Hardness properties and microscopic investigation of crack-crystal interaction in $\mathrm{SiO}(2)-\mathrm{MgO}-\mathrm{Al}$ (2)O (3)-K (2)O-B (2)O (3)-F glass ceramic system. Journal of Materials Science: Materials in Medicine. 2009; September15.DOI 10.1007/s10856-009-3853-7. Present status: under publication.

16. Hubbezoglu I, Bolayir G, Dogan OM, Dogan A, Ozer A and Bek B. Microhardness evaluation of resin composites polymerized by three different light sources. Dental Materials Journal. 2007; 26(6):845-53.

17. Eldiwany M, Powers JM and George LA. Mechanical properties of direct and post-cured composites. American Journal of Dentistry. 1993; $6(5): 222-4$

18. Greener EH, Greener CS and Moser JB. The hardness of composites as a function of temperature. Journal of Oral Rehabilitation. 1984; 11(4):335-40.

19. McCabe JF and Wassell RW. Hardness of model dental composites the effect of filler volume fraction and silanation. Journal of Materials Science: Materials in Medicine. 1999; 10(5):291-4.

20. Reed B, Choi K, Dickens S and Stansbury J. Effect of resin composition on kinetics of dimethacrylate photopolymerization. American Chemistry Society: Polymer Preprints. 1997; 38(2):108-9. 
21. Pereira SG, Osorio R, Toledano M, Cabrerizo-Vilchez MA, Nunes TG and Kalachandra S. Novel light-cured resins and composites with improved physicochemical properties. Dental Materials. 2007; 23(10):1189-98.

22. Ferracane JL. Correlation between hardness and degree of conversion during the setting reaction of unfilled dental restorative resins. Dental Materials. 1985; 1(1):11-4.

23. Lindberg A, Peutzfeldt A and van Dijken JW. Effect of power density of curing unit, exposure duration, and light guide distance on composite depth of cure. Clinical Oral Investigations. 2005; 9(2):71-6.

24. Palin WM, Fleming GJ, Burke FJ, Marquis PM and Randall RC. Monomer conversion versus flexure strength of a novel dental composite. Journal of Dentistry. 2003; 31(5):341-51.

25. Palin WM, Fleming GJ, Burke FJ, Marquis PM and Randall RC. The influence of short and medium-term water immersion on the hydrolytic stability of novel low-shrink dental composites. Dental Materials. 2005; 21(9):852-63.

26. Decker C, Viet $\mathrm{C}$ and Thi H. Photoinitiated cationic polymerization of epoxides. Polymer International. 2001; 50(9):986-97.

27. Oréfice RL, Discacciati JAC, Neves AD, Mansur HS and WC J. Material Behaviour In situ evaluation of the polymerization kinetics and corresponding evolution of the mechanical properties of dental composites. Polymer Testing. 2003; 22(1):77-81.

28. Pilo R and Cardash HS. Post-irradiation polymerization of different anterior and posterior visible light-activated resin composites. Dental Materials. 1992; 8(5):299-304.

29. Eliades GC, Vougiouklakis GJ and Caputo AA. Degree of double bond conversion in light-cured composites. Dental Materials. 1987; 3(1):19-25

30. Ferracane JL and Greener EH. The effect of resin formulation on the degree of conversion and mechanical properties of dental restorative resins. Journal of Biomedical Materials Research. 1986; 20(1):121-31.
31. Tarumi H, Imazato S, Ehara A, Kato S, Ebi N and Ebisu S. Post-irradiation polymerization of composites containing bis-GMA and TEGDMA. Dental Materials. 1999; 15(4):238-42.

32. Ciccone-Nogueira JC, Borsatto MC, Souza-Zaron WC, Ramos RP and Palma-Dibb RG. Microhardness of composite resins at different depths varying the post-irradiation time. Journal of Applied Oral Science. 2007; 15(4):305-9.

33. Chung $\mathrm{K}$ and Greener EH. Degree of conversion of seven visible light-cured posterior composites. Journal of Oral Rehabilitation. 1988; 15(6):555-60.

34. Asmussen E. Factors affecting the quantity of remaining double bonds in restorative resin polymers. Scandinavian Journal of Dental Research. 1982; 90(6):490-6.

35. Quance SC, Shortall AC, Harrington E and Lumley PJ. Effect of exposure intensity and post-cure temperature storage on hardness of contemporary photo-activated composites. Journal of Dentistry. 2001; 29(8):553-60.

36. Hansen E. After-polymerisation of visible light-activated resins: surface hardness vs light source. Scandinavian Journal of Dental research. 1983; 91(5):406-10.

37. Cefaly DF, Ferrarezi GA, Tapety CM, Lauris JR and Navarro MF Microhardness of resin-based materials polymerized with LED and halogen curing units. Brazilian Dental Journal. 2005; 16(2):98-102.

38. Manhart J, Kunzelmann KH, Chen HY and Hickel R. Mechanical properties of new composite restorative materials. Journal of Biomedical Materials Research. 2000; 53(4):353-61.

39. Asmussen E and Peutzfeldt A. Influence of UEDMA BisGMA and TEGDMA on selected mechanical properties of experimental resin composites. Dental Materials. 1998; 14(1):51-6.

40. Hubbezoğlu I, Bolayir G, Doğan OM, Doğan A, Özer A and Bek B. Microhardness evaluation of resin composites polymerized by three different light sources. Dental Material Journal. 2007; 26(6):845-53. 
